\title{
A PRÁXIS EM DUAS EXPERIÊNCIAS DISTINTAS EM EDUCAÇÃO E A IMPORTÂNCIA DA PEDAGOGIA HISTÓRICO-CRÍTICA
}

\section{THE PRACTICES IN TWO DIFFERENT EXPERIENCES IN EDUCATION AND THE IMPORTANCE OF HISTORICAL-CRITICAL PEDAGOGY}

\author{
Debora Mota Marques ${ }^{1}$ \\ Maria Aparecida de Lima Braga Fernandes ${ }^{2}$
}

\section{Resumo:}

Este artigo tem como objetivo geral analisar a nossa práxis enquanto trabalhadoras em educação, sendo a primeira a práxis no setor de gerência e supervisão pedagógica de um Instituto Federal de Educação, Ciência e Tecnologia e a segunda, na docência da modalidade de Jovens e Adultos. A metodologia utilizada foi a de trazer e analisar as experiências aqui citadas à luz do materialismo histórico-dialético. Verificou-se que não há práxis neutra, toda práxis tem uma finalidade, seja para a conservação da sociedade, seja para a sua transformação. Apontamos a pedagogia histórico-crítica como muito importante na formação dos profissionais da educação para que eles mesmos tenham condições de fazer reflexões sobre suas práticas e possam problematizar, questionar e, por conseguinte, tornarem-se menos alienados e mais reflexivos.

Palavras - chaves: práxis espontânea/reiterativa; práxis criadora/reflexiva; trabalho do pedagogo; trabalho docente.

\begin{abstract}
:
This article has the general objective of analyzing our praxis as workers in education, the first being the praxis in the pedagogical management and supervision sector of a Federal Institute of Education, Science and Technology and the second one teaching young people and adults. The methodology used was to bring and analyze the experiences mentioned here in the light of historical-dialectical materialism. It has been found that there is no neutral praxis, every praxis has a purpose, either for the conservation of society or for its transformation. We point out the importance of historical-critical pedagogy in the formation of educational professionals so that they themselves can reflect on their practices and can problematize, question and therefore become less alienated and more reflective.
\end{abstract}

Key words: Spontaneous / repetitive praxis. Creative / reflective praxis. Work from pedagogue. Teaching work.

\footnotetext{
${ }^{1}$ Mestre em Educação pela Universidade Federal de Viçosa, especialista em Gestão Escolar: Orientação e Supervisão e pedagoga pela Universidade Federal Fluminense. Aatualmente é pedagoga no Instituto Federal de Educação, Ciência e Tecnologia do Sudeste de Minas Gerais, campus Muriaé - debora.mota@ifsudestemg.edu.br.

${ }^{2}$ Mestre em Educação pela Universidade Federal de Viçosa, especialista em Literatura Brasileira e Portuguesa, também especialista em Língua Portuguesa e graduada em Letras pela FASM (Faculdade Santa Marcelina). Atualmente, é professora de Língua Portuguesa do Ensino Médio/EJA semipresencial no CESEC Governador Bias - Muriaé-MG) - cidabrafernan@ yahoo.com.
} 


\title{
INTRODUÇÃO
}

Este artigo tem como objetivos apresentar o conceito de práxis (VÁZQUEZ, 2007) dentro de uma concepção materialista-dialética, descrever e analisar a práxis em duas experiências em contextos escolares distintos e, ainda, mostrar a importância da pedagogia histórico-crítica (BATISTA \& LIMA, 2015) aos trabalhadores da educação.

A escolha de trabalhar a questão da práxis nessas duas situações se deve à nossa atuação como profissionais e como pesquisadoras em instituições e em experiências distintas - somos, respectivamente, pedagoga em um Instituto Federal e professora na modalidade de Educação de Jovens e Adultos.

$\mathrm{Na}$ introdução deste trabalho, traremos o conceito de práxis de acordo com Vásquez (2007), para que, a partir desse referencial, possamos analisar e discutir as nossas práxis como profissionais da educação e mostrarmos a importância da pedagogia históricocrítica na formação dos trabalhadores dessa área.

\section{O CONCEITO DE PRÁXIS}

Vázquez (2007) trabalha o conceito de práxis em diferentes graus os quais serão de fundamental importância para analisar as duas experiências que apresentaremos. Apresentaremos o conceito de práxis criadora diante da prática reiterativa e da práxis espontânea diante da práxis reflexiva.

\begin{abstract}
A práxis criadora, entretanto, não se dá apenas no âmbito da arte, mas também no âmbito da inovação teórica e da práxis revolucionária enquanto transformadoras da realidade; uma no nível conceitual, e a outra no nível da organização social, são exemplos de práxis criadoras na medida em que mostram a unidade do objetivo e do subjetivo ao longo do processo prático, assim como porque produzem algo único e irrepetível, e que era imprevisível no início da atividade (VÁZQUEZ, 2007, p. 15).
\end{abstract}

Sobre a práxis criadora, é válido destacar que é aquela dotada de mais liberdade e de maior autonomia. Além disso, é uma práxis única, que não se repete. Trata-se de uma práxis criada a partir de uma situação. Ao mesmo tempo, é uma práxis preocupada com a transformação da realidade, pois, a partir da situação vivida, o indivíduo planeja e executa algo com objetivo de transformação.

Diferente dessa perspectiva, temos a práxis reiterativa. Essa, ao contrário do aspecto da criação, se dá de forma repetitiva:

(...) práxis meramente imitativa reduz o caráter de unicidade, irrepetibilidade e imprevisibilidade do produto, já que ao partir de um determinado modelo a imitar, considerado não passível de aperfeiçoamento, sua capacidade criativa se anula. (...) o trabalho mecanizado da cadeia de montagem taylorista e fordista como exemplos 
de práxis imitativa e repetitiva nas quais a atividade intelectual criativa se dissocia da mera execução mecânica, fazendo a mão humana perder seu caráter criador e poético em sentido etimológico (VÁZQUEZ, 2007, p. 15).

A práxis reiterativa assume um caráter mecânico e sem sentido. Dá ênfase ao fazer seguindo um modelo, ou seja, é uma práxis que tira o potencial criativo dos indivíduos.

Vázquez (2007) apresenta a práxis espontânea e a práxis reflexiva. A diferença entre as duas está pautada na força maior que a segunda tem em relação à primeira no que diz respeito a um elevado grau de consciência envolvido na prática. A segunda supõe a reflexão sobre a prática e tem um caráter transformador. A primeira tem um grau muito menor de consciência, quase inexistente.

É preciso que deixemos claro que, em ambos os graus de práxis, exige-se algum tipo de consciência, entretanto, a criadora, por exemplo, exige um grau maior de consciência quanto à atividade que se realiza. Em contrapartida, o grau de consciência em uma reiterativa é muito menor, ou quase nulo, pois é algo extremamente mecânico, em que não há espaço para problematizar, dialogar ou intervir de forma a transformar a realidade.

Levando em consideração as contribuições de Vázquez (2007), entendemos pertinente trazer uma ilustração para apresentar tais conceitos:

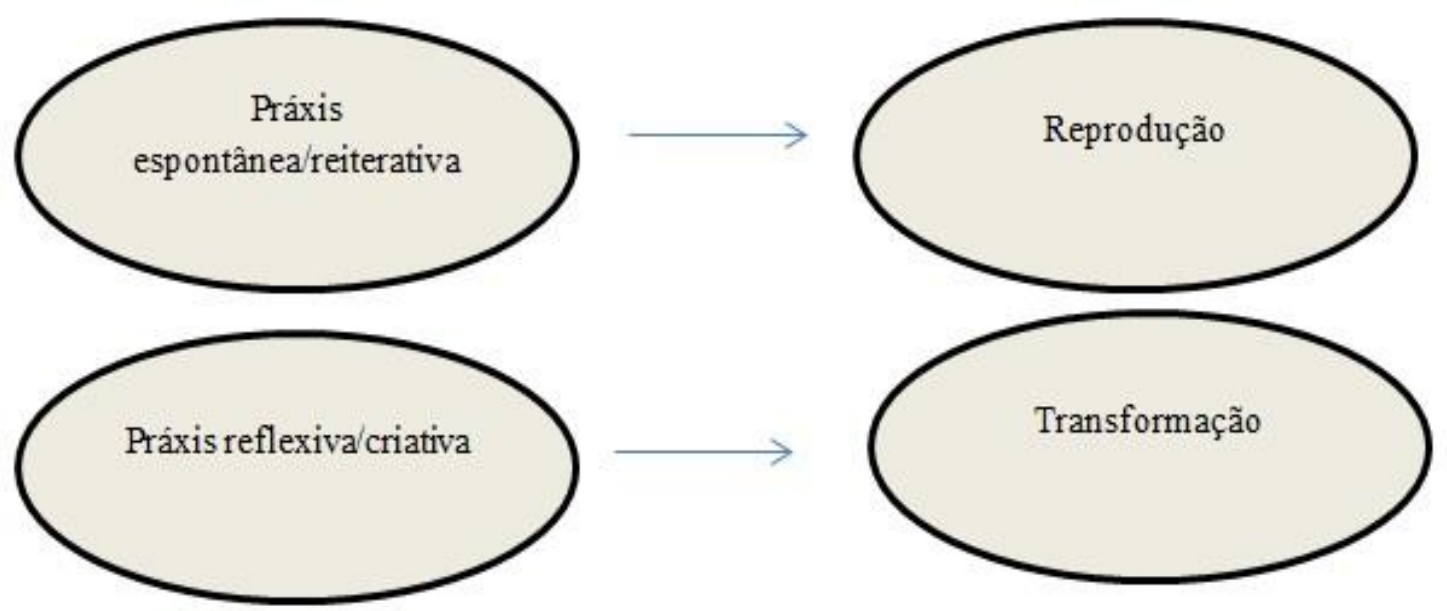

Figura 1: Os graus de práxis de acordo com Vásquez (2007) Fonte: Elaborado pelas autoras (2019)

Ao elaborarmos essa imagem, buscamos demonstrar que, de acordo com o grau de práxis, o indivíduo reproduz ou transforma sua prática e, assim, sua realidade. É necessário, entretanto, deixar bem claro que, em ambas as práxis, existe um grau de consciência, a diferença se encontra no grau de consciência de cada uma. Por isso, quando o grau de consciência é menor, como no caso da práxis espontânea e reiterativa, há maior possibilidade 
para a reprodução; quando o grau de consciência é maior, como no caso da práxis reflexiva e criativa, há maior probabilidade de transformação dessa ação. Quando se reflete sobre a práxis, há um grande potencial de transformação sobre ela. Assim sendo, o autor traz a importância da consciência da prática, que é mais ampla que a consciência prática.

Outro ponto que é válido ser destacado em relação aos graus de práxis é que podem acontecer vínculos entre eles, ou seja, poderão ocorrer práxis reprodutoras e transformadoras juntas. Nem sempre ocorrerão apenas práxis reprodutoras ou apenas transformadoras. É isso que percebemos na história, ela vai se construindo como práxis conservadora e transformadora. Se houvesse somente práxis transformadoras, por exemplo, não estaríamos vivendo momentos de golpe à democracia ou de apoio à ditadura militar e de clamor por sua volta.

Dito isso, é importante problematizar: em que grau se encontra a práxis de docentes e trabalhadores da educação? Ou, ainda, o que impede que a práxis dos trabalhadores da educação seja mais reflexiva e criativa?

Os professores, de um modo geral, são levados a realizar uma práxis reiterativa, imitativa, uma vez que perdem a noção do sentido do seu trabalho, sufocados que são pelas práticas liberais. Tais práticas tiram da escola a capacidade de realizar uma práxis revolucionária que possa promover uma formação verdadeiramente humana, pois impõem, por exemplo, um currículo que pretende atender às expectativas das avaliações externas, assim como atividades determinadas por instâncias que desconhecem o chão da escola, como os reformadores empresariais da educação, no Brasil representados pelo movimento Todos pela Educação. Além disso, a precarização e a intensificação do trabalho docente esgotam as forças do professor, que se rende à realização de uma práxis descomprometida com a transformação da sociedade.

\section{METODOLOGIA}

Neste trabalho, optamos por analisar nossas experiências como trabalhadoras da educação em dois diferentes contextos: trabalho realizado no setor de gerência e supervisão pedagógica do Instituto Federal de Educação, Ciência e Tecnologia do Sudeste de Minas Gerais; e, referente ao trabalho realizado na docência, na modalidade de Educação de Jovens e Adultos.

Desenvolvemos metodologia de análise sustentada pelo materialismo históricodialético, pois "estabelece-se como tentativa de busca das explicações lógicas, coerentes e racionais para os fenômenos naturais, sociais e do pensamento" (TRIVIÑOS, 1987). No caso específico deste trabalho, que aborda duas práxis em contextos diferentes da educação, 
podemos perceber uma relação dialética entre teoria e prática, visto que a prática revela uma teoria.

Segundo Franco, Carmo e Medeiros (2014) "a visão do mundo na dialética pode partir do particular para se vislumbrar o universal ou parte do universal para se ter entendido com clareza o particular". É esse movimento que queremos fazer - realizar a análise de duas práxis (particular) em dialética com a sociedade capitalista na qual estamos inseridas (universal) e ver como esse movimento influencia as nossas práxis.

Sabemos que as pesquisas crítico-dialéticas se configuram nos "estudos sobre experiências, práticas pedagógicas, processos históricos, discussões filosóficas ou análises contextualizadas a partir de um prévio referencial teórico" (GAMBOA In FAZENDA, 2010. p. 106 apud FRANCO, CARMO e MEDEIROS, 2014, p. 94).

\begin{abstract}
As pesquisas crítico-dialéticas (terceiro grupo) questionam fundamentalmente a visão estática da realidade implícita nas abordagens anteriores. Esta visão esconde o caráter conflitivo, dinâmico e histórico da realidade. Sua postura marcadamente crítica expressa a pretensão de desvendar, mais que o "conflito das interpretações", o conflito dos interesses. Essas pesquisas manifestam um "interesse transformador" das situações ou fenômenos estudados, resguardando sua dimensão sempre histórica e desvendando suas possibilidades de mudanças (GAMBOA, 2010. p. 107-108 apud FRANCO, CARMO E MEDEIROS, 2013, p. 94-95).
\end{abstract}

Portanto, neste trabalho, analisaremos nossas práxis atentando para o fato de que elas não podem se revelar de forma neutra. Toda práxis revela uma teoria, logo está a serviço de algum interesse. Ainda sobre essa metodologia, ressaltamos que é característica da mesma apontar possibilidades de mudanças após a análise contextualizada das práticas.

\title{
RESULTADOS E DISCUSSÕES:
}

\section{A práxis em dois contextos diferentes da educação}

A práxis no setor de Gerência e Supervisão Pedagógica no Instituto Federal de Educação, Ciência e Tecnologia do Sudeste de Minas Gerais

Primeiramente, é importante que o leitor saiba que o pedagogo do Instituto Federal de Educação, Ciência e Tecnologia, de acordo com a Lei $n^{\circ} 11.091 / 2005^{3}$, é reconhecido como Técnico Administrativo em Educação. Em contrapartida, a Lei de Diretrizes e Bases da Educação Nacional n 9394/96 o reconhece como profissional da educação ${ }^{4}$.

\footnotetext{
${ }^{3}$ Dispõe sobre a estruturação do Plano de Carreira dos Cargos Técnico-Administrativos em Educação, no âmbito das Instituições Federais de Ensino vinculadas ao Ministério da Educação, e dá outras providências.

${ }^{4}$ TÍTULO VI - Dos Profissionais da Educação- Art. 61. Consideram-se profissionais da educação escolar básica os que, nela estando em efetivo exercício e tendo sido formados em cursos reconhecidos, são: II - trabalhadores em educação portadores de diploma de pedagogia,
} 
Ao colocarmos em evidência o profissional como técnico, partindo de uma concepção liberal, poderíamos falar em separação entre teoria e prática e/ou entre trabalhos intelectuais e práticos. Em uma concepção bem simples, poderíamos dizer então - levando em conta o conceito que os liberais apontam como dualidade entre teoria e prática -, que o pedagogo seria aquele profissional responsável por ter um conhecimento prático.

Duarte (2006, p. 100), ao fazer referência a Gramsci, pontua algumas considerações sobre a interpretação equivocada que ainda prevalece em nossa sociedade e nas divisões de trabalho: "[...] não existe atividade humana da qual se possa excluir toda intervenção intelectual, não se pode separar o homo faber do homo sapiens, e este é o eixo norteador do seu princípio educativo".

Nesse sentido, podemos relatar que não se pode separar prática de teoria. Ou, ainda, mesmo que se diga que um profissional é técnico, há de se destacar que é preciso olhar o conceito para além de uma prática descolada da teoria. Quando se diz que um profissional é técnico, há de se destacar uma forte influência do tecnicismo e da tentativa de neutralizar as práticas.

Dito isso, apresentamos algumas das práticas em um Instituto Federal ${ }^{5}$ :

1 - Organizar, controlar e avaliar a execução dos projetos de curso Técnico e as demais atividades didático-pedagógicas do ensino.

Essa atribuição dada ao pedagogo diz respeito à conferência da matriz curricular e da carga horária dos cursos com o objetivo de observar se está atendendo ao que é determinado pelo Ministério da Educação.

Considerando o grau de consciência necessário para esse tipo de práxis e conhecendo as normas, as legislações educacionais e as diretrizes curriculares dos cursos, podemos dizer que o profissional consegue exercer essa função. Podemos também afirmar que há certo grau de consciência ao realizar essa atividade. Entretanto, não podemos dizer que nessa ação há a força de uma práxis reflexiva, pois não há aí problematização ou reflexão, visto que essa prática se refere a seguir um modelo que é proposto pelo Ministério da Educação. O pedagogo observa, compara e avalia esses cursos seguindo modelos solicitados pela Secretaria de Educação.

Logo, não há espaço para uma práxis criativa e/ou reflexiva, pois a escola é cobrada para atender a essas normas. Nesse caso, a práxis gira, então, em torno de seguir o modelo proposto. Diferentemente dessa, a práxis reflexiva faz com que o indivíduo

com habilitação em administração, planejamento, supervisão, inspeção e orientação educacional, bem como com títulos de mestrado ou doutorado nas mesmas áreas;

${ }^{5}$ Atribuições do pedagogo no Instituto Federal de Educação, Ciência e Tecnologia de acordo com o regulamento interno do Campus. 
problematize, avalie e tenha uma ação diferente da que foi proposta. Dessa forma, seria o sentido inverso, seria olhar o que vem determinado para os cursos e problematizar o motivo pelo qual uma carga horária é maior para determinada disciplina e menor para outras, por exemplo, é questionar junto aos professores que tipo de autonomia é dada se temos que, a todo momento, obedecer a modelos prontos, seria perguntar qual a força de uma gestão democrática para levantar o que realmente é de importância para a escola e para o curso.

2 - Elaborar o calendário letivo

Elaborar o calendário escolar requer do pedagogo o conhecimento das exigências das leis educacionais no que diz respeito à quantidade de dias letivos e cargas horárias, como observado na Lei de Diretrizes e Bases da Educação Nacional n 9394/96, nos artigos 23 e 24:

Art. 23. A educação básica poderá organizar-se em séries anuais, períodos semestrais, ciclos, alternância regular de períodos de estudos, grupos não-seriados, com base na idade, na competência e em outros critérios, ou por forma diversa de organização, sempre que o interesse do processo de aprendizagem assim o recomendar.

$\S 1^{\circ} \mathrm{A}$ escola poderá reclassificar os alunos, inclusive quando se tratar de transferências entre estabelecimentos situados no País e no exterior, tendo como base as normas curriculares gerais.

$\S 2^{\circ} \mathrm{O}$ calendário escolar deverá adequar-se às peculiaridades locais, inclusive climáticas e econômicas, a critério do respectivo sistema de ensino, sem com isso reduzir o número de horas letivas previsto nesta Lei.

Art. 24. A educação básica, nos níveis fundamental e médio, será organizada de acordo com as seguintes regras comuns:

I - a carga horária mínima anual será de oitocentas horas para o ensino fundamental e para o ensino médio, distribuídas por um mínimo de duzentos dias de efetivo trabalho escolar, excluído o tempo reservado aos exames finais, quando houver;

(BRASIL, 1996 - grifo nosso).

Esse é um tipo de práxis que requer, uma vez mais, pouca conscientização do pedagogo. Mais uma vez, seria elaborar o calendário escolar obedecendo à Lei Educacional, ou seja, elaborar um calendário significa saber a organização do curso - anual, semestral, trimestral ou bimestralmente e dividir os duzentos dias letivos no calendário para atender aos artigos acima apresentados.

Entretanto, olhando por uma práxis reflexiva, o pedagogo poderia junto aos professores refletir sobre o que seria feito no próximo ano letivo. A práxis reflexiva torna o profissional um indivíduo que questiona a sua própria prática.

Seria válido analisar, questionar e problematizar certas práticas e pensá-las de forma diferenciada. Logo, a elaboração do calendário poderia ser entendida como momento de reflexão da ação do ano anterior para ter uma ação refletida diferente no ano seguinte.

3- Assegurar a fiel observância dos planos e programas de ensino, bem como do regime didático e das resoluções do Conselho de Campus e adotar medidas corretivas quando necessárias. 
Nessa atribuição, vemos o modelo gerencial e administrativo na gestão da educação. Isso significa dizer que é preciso supervisionar os planos e programas de ensino para observar se estão de acordo com a produção de resultados esperada pela Secretaria de Educação/MEC. Além disso, diz respeito à cobrança aos professores para a entrega de diários e/ou outros tipos de documentos institucionais. Mais uma vez, a questão da repetição, práxis em que se exige do profissional verificar se planos e programas atendem a um requisito.

O diferencial seria uma práxis em que se questionasse o modelo imposto, uma práxis em que problemas fossem levantados, tendo em vista a reflexão sobre quais seriam os motivos para que tais modelos sejam seguidos.

Inseridos em uma sociedade capitalista, o que acontece é que há uma alienação dos trabalhadores. A ação do trabalhador ocorre em torno de atingir um modelo, de obedecer a um padrão de produção em que, cada vez mais, somos explorados e alienados. O trabalhador já não tem consciência de si, não faz reflexão de sua prática, pois a sua prática, ou melhor, o produto de sua prática, na maior parte das vezes, é estranho para si, uma vez que, no capitalismo, o trabalhador não se reconhece no produto final.

Esse processo é histórico, social, econômico e atinge a todos os trabalhadores. Portanto, não há como olhar as práxis como neutras e isoladas. Por isso, destacamos que certas práxis nos levam para a reprodução dessa sociedade e outras nos levam à transformação da mesma.

O que fica claro com as atribuições dadas é que tanto a legislação que diz respeito ao pedagogo como técnico administrativo em educação quanto as políticas institucionais apontam para um profissional técnico. Dizer que um profissional é técnico implica dizer que apenas tem a prática. Logo, percebemos, mais uma vez, a separação entre trabalho intelectual e manual. Isso é perigoso, pois focar apenas na prática pela prática demonstra uma práxis cujo grau de consciência é quase nulo, que leva o trabalhador à alienação. Na verdade, a práxis precisa ser questionada e problematizada para que não ocorra a reprodução desse tipo de sociedade em que estamos vivendo. $O$ trabalhador alienado não conhece a si mesmo, não reflete sobre suas ações, logo não tem práxis reflexivas.

Por isso é necessário que o profissional consiga olhar e problematizar suas práxis. E, principalmente, ter consciência de que práxis reiterativas e espontâneas ocultam muitas vezes o caráter social e transformador da práxis. Assim sendo, sempre é preciso olhar para a práxis problematizando que tipo de homem e que tipo de sociedade dela podem resultar. 


\section{A práxis na docência da modalidade de Educação de Jovens e Adultos}

É difícil realizar uma práxis revolucionária e transformadora nessa modalidade, uma vez que os alunos estão acostumados a copiar e a reproduzir, e os professores nem sempre se mostram preparados para compreender os vínculos de sua prática com a prática social global, sofrem com a invasão da escola pelos reformadores empresariais da educação, com a perda de autonomia sobre o seu trabalho, com a falta de um plano de carreira, com a sobrecarga de trabalho e com os baixos salários.

Como as escolas estaduais são fortemente influenciadas pelo sistema capitalista, que coloca a educação à mercê dos interesses das classes hegemônicas, a práxis do professor dessa esfera muito se assemelha à de outras redes, sobretudo públicas, pois tende a almejar a reprodução, não a transformação. Aliás, o capitalismo é altamente corrosivo e atinge a quase totalidade das escolas, sejam elas municipais, estaduais, federais, sejam elas públicas ou particulares, com maior ou menor intensidade. Tratando-se especificamente das escolas de jovens e adultos da rede estadual, não há como não perceber a influência capitalista reverberando infinitamente e cerceando a práxis dos professores, o que pode ser constatado ao considerarmos a difícil realidade das escolas:

a) o grande número de estudantes que chegam à escola para atender a uma demanda do mercado. Pessoas que procuram a escola não porque querem transformar a própria vida e a vida da sua comunidade, sendo o seu propósito normalmente determinado pelos patrões, que, estando necessitados de uma mão de obra mais especializada, que produza mais lucro para os seus próprios bolsos, exigem que seus funcionários voltem aos bancos escolares.

b) o número significativo de alunos que desistem de continuar os estudos pela incompatibilidade entre trabalho e escola. Diante da impossibilidade de conciliar trabalho e escola, optam pelo trabalho, isso porque realizam um trabalho alienado, que se perpetua na impossibilidade de romperem com o círculo vicioso que os prende a esse trabalho que não irá levá-los ao desenvolvimento, à dignidade, mas sem o qual eles não podem ficar.

c) A ditadura da cópia, da padronização e da meritocracia, que transforma a escola em um espaço em que a criatividade e a parceria colaborativa não tenham lugar, em um palco de disputas onde aqueles que conseguem assimilar os conhecimentos são absorvidos pelo mercado de trabalho, sendo os demais desprezados e oprimidos. A meritocracia culpabiliza o indivíduo, responsabiliza-o por seu fracasso ou sucesso, sem levar em conta as reais 
condições econômicas e sociais em que cada indivíduo se encontra. Sobre meritocracia, Freitas (2012) alerta:

Ela está na base da proposta política liberal: igualdade de oportunidades e não de resultados. Para ela, dadas as oportunidades, o que faz a diferença entre as pessoas é o esforço pessoal, o mérito de cada um. Nada é dito sobre a igualdade de condições no ponto de partida. No caso da escola, diferenças sociais são transmutadas em diferenças de desempenho e o que passa a ser discutido é se a escola teve equidade ou não, se conseguiu ou não corrigir as "distorções" de origem, e esta discussão tira de foco a questão da própria desigualdade social, base da construção da desigualdade de resultados (FREITAS, 2012, p. 383).

Assim sendo, percebemos que a meritocracia é concepção de um modelo liberal de educação que favorece uns em detrimento de outros. Portanto, usar a meritocracia na escola é aceitar que é esse o tipo de homem e sociedade que se quer formar - indivíduos responsáveis por seus fracassos ou sucessos -, neutralizando, dessa forma, as contradições e condições sociais e políticas dessa sociedade.

d) o corpo docente que, quase em sua totalidade, trabalha em duas ou em até três escolas para garantir um salário que dê para viver com alguma dignidade. Estando frequentemente ocupados, indo de uma escola para outra, sobrecarregados com tantas tarefas, os professores têm dificuldade de reconhecer o sentido transformador do seu trabalho. Esse conjunto de situações os impede de alcançar um grau de consciência mais elevado, afastando-os de uma práxis revolucionária.

Ao considerarmos essa realidade educacional, que é fruto dos interesses do capital, podemos perceber a dificuldade para que se realize, nas escolas, uma práxis criadora e reflexiva.

É fundamental, portanto, que apresentemos a importância de uma pedagogia histórico-crítica aos trabalhadores da educação, principalmente por ser ela uma pedagogia libertadora e questionadora, que se configura como instrumento de mudança.

\section{A importância da pedagogia histórico-crítica para os trabalhadores da educação}

Como visto anteriormente, a práxis do indivíduo por vezes se restringe a uma práxis com graus menores de conscientização sobre ela. Nesse sentido, debatemos a importância da pedagogia histórico-crítica para o trabalhador da educação, permitindo que ele tenha condições de refletir sobre suas práticas, para que possa problematizar, questionar e, por conseguinte, se tornar menos alienado e mais reflexivo. 
Cada pedagogia tem um fim, uma concepção, princípios e, logo, metodologias. Dessa forma, podemos dizer que tanto as pedagogias progressistas quanto as liberais possuem suas concepções e princípios. A pedagogia liberal ${ }^{6}$ objetiva a ausência de questionamentos, por isso forma profissionais que se adaptem à sociedade, forma indivíduos que se adaptem à realidade, sem contestá-la. Assim sendo, o grau de conscientização reflexiva e criativa dos indivíduos formados nessa perspectiva é restrito ou quase nulo.

Em contrapartida, as pedagogias progressistas têm por objetivo principal o questionamento e a problematização da realidade. São pedagogias preocupadas com as questões sociais, com a formação dos indivíduos no sentido de transformar sua realidade. Logo, a ênfase é dada à importância da conscientização dos indivíduos para que esses tenham ferramentas de questionamentos e problematizações para mudar realidade em que vivem. Diferente da pedagogia liberal, as pedagogias progressistas não querem que o indivíduo se adapte à realidade, mas, sim, transforme-a.

É necessário destacar que a educação está inserida na sociedade capitalista, marcada
pela dominação de classe. A classe dominante não possui nenhum interesse na
transformação histórica da escola, pelo contrário, empenhando-se na manutenção de
seu domínio. Sendo a escola determinada socialmente, coloca-se a seguinte questão:
"[...] é possível articular a escola com os interesses dos dominados?" (SAVIANI,
2009, p. 28 apud BATISTA \& LIMA, 2015, p. 169).

Há que se levar em conta a sociedade capitalista em que vivemos. Ela é marcada pela dominação das classes hegemônicas, por isso, na maioria das vezes, a escola, os professores e profissionais da educação praticam determinadas práxis em que essa reprodução é possível. É o contrário, entretanto, que queremos apresentar. É necessário que o indivíduo tenha consciência de sua ação e se questione se essa ação tem reproduzido ou transformado a realidade.

(...) a prática docente deve ser pensada a partir do entendimento da função da escola, da função do educador nesta escola. Se a escola corresponde a uma importante objetivação humana, local por excelência para a transmissão do conhecimento técnico-científico e humanístico acumulado historicamente, a prática docente deve ser desenvolvida na perspectiva da formação plena do ser social (BATISTA \& LIMA, 2015, p. 175).

É fundamental que ressaltemos que a real função dos trabalhadores da educação dentro de uma pedagogia histórico-crítica é questionar qual a função da escola. A quem essa escola atende? Que tipo de sociedade e homem queremos formar? É a partir desses

\footnotetext{
${ }^{6}$ Segundo Libâneo (2001) o termo liberal não tem sentido de avançado, democrático, aberto, como costuma ser usado. A pedagogia liberal é uma manifestação própria da sociedade capitalista. Libâneo (2001) alerta que a pedagogia liberal sustenta a ideia de que a escola tem por função preparar o indivíduo para o desempenho de papeis sociais de acordo com suas aptidões. Portanto, esses indivíduos precisam se adaptar aos valores e normas vigentes da sociedade por meio do desenvolvimento da cultura individual. Ainda segundo Libâneo (2001) tais tendências se manifestam, concretamente, nas práticas escolares e no ideário pedagógico de muitos professores, ainda que estes não deem conta dessa influência. Ver mais em: LIBÂNEO, José Carlos. Democratização da escola pública. Edições Loyola, 2001.
} 
questionamentos que os profissionais podem começar a problematizar suas práxis, também interrogando se servem para a reprodução ou para a transformação dessa sociedade. Com isso, atentaremos para o fato de que as práxis não são isoladas ou neutras, possuem funções reativas, de rompimentos ou têm ambas as funções.

Outro elemento fundamental da pedagogia histórico-crítica, apontado na definição do trabalho educativo elaborada por Saviani, é a centralidade da consciência histórica do desenvolvimento humano, o que Gramsci denominou de "conhece-te a ti mesmo" (GRAMSCI, 2006, p. 302 apud BATISTA \& LIMA, 2015, p. 175).

Somente por meio da consciência filosófica os professores podem realizar a catarse que os levará a uma prática social transformadora. Gramsci assim define catarse:

Pode-se empregar a expressão "catarse" para indicar a passagem do momento puramente econômico (ou egoísta-passional) ao momento ético-político, isto é, a elaboração superior da estrutura em superestrutura na consciência dos homens. Isto significa, também, a passagem do "objetivo ao subjetivo" e da necessidade à liberdade. A estrutura da força exterior que subjuga o homem, assimilando-o e o tornando passivo, transforma-se em meio de liberdade, em instrumento para criar uma forma ético-política, em origem de novas iniciativas (GRAMSCI, 2006, p. 314).

Parece óbvio pensar que o momento catártico é crucial no trabalho docente, certamente ninguém duvida de que ele possa suscitar "novas iniciativas", mas por que ele não é garantido aos professores? Por que é possível que um professor passe toda a sua vida profissional sem refletir sobre ela, sem questionar a sua práxis? Certamente a resposta seria porque essa prática levaria os docentes a transformarem a sociedade, o que incomodaria a classe dominante, que não possui nenhum interesse na transformação histórica da escola e, consequentemente, da sociedade, pelo contrário, está sempre se esmerando na perpetuação de seu domínio.

Há que se problematizar, ainda, qual é a formação desses profissionais da educação. Um profissional da educação que é formado nos moldes da pedagogia liberal dificilmente consegue ter uma pedagogia progressista em sua práxis. Na maioria dos cursos de formação de professores, o currículo tem como foco a parte conteudista e especialista da formação. Isso faz com que a abordagem política, filosófica e social da formação seja descartada, ficando esses profissionais sem uma formação integral. Com essa formação tecnicista, o profissional tende a ensinar a fazer sem problematizar, sem refletir sobre quais implicações as ações realizadas resultam.

É preciso que se olhe a práxis dos profissionais da educação levando-se em conta o tipo de educação que receberam em suas formações e/ou em suas formações continuadas. 
Presenciamos em muitas universidades que o interesse é simplesmente este: oferecer uma educação tecnicista, o que atende aos interesses do capital, pois nela não há espaço para os indivíduos problematizarem, questionarem e agirem de forma transformada.

Para um profissional problematizar a sua práxis, é fundamental que a desnaturalize ou, melhor dizendo, que a olhe entendendo que ela não é neutra. Para tanto, a formação desse profissional também precisará ser libertadora.

\section{CONCLUSÃO}

Deixamos como apontamento final a necessidade de o profissional da educação cada vez mais conhecer a si mesmo e refletir sobre sua práxis. Nesse sentido, também apontamos a pedagogia histórico-crítica como fundamental para os docentes e profissionais da educação, pois ela é instrumento para transformação social.

Tanto no setor de Gerência e Supervisão Pedagógica de um Instituto Federal quanto na docência da modalidade da EJA é visível uma macroestrutura que influencia a nossa práxis enquanto trabalhadoras. Entretanto, uma práxis questionadora faz com que reflitamos sobre nossas ações no sentido de perguntarmos qual é a finalidade dessa práxis.

Algo extremamente importante que queremos deixar ao leitor é que não há práxis neutra, toda práxis tem uma finalidade, seja a conservação da sociedade, seja a sua transformação. Ou, ainda, aquelas que ora conservam, ora transformam, em um movimento próprio da história. Por esse motivo, optamos por apresentar as práxis de acordo com Vázquez (2007), pois ele nos proporciona o entendimento de que sempre há um fim em qualquer uma, independentemente de qual seja. Cabe a nós, profissionais da educação, estarmos atentos a isso, sempre questionando e problematizando nossas práxis.

\section{REFERÊNCIAS BIBLIOGRÁFICAS:}

BATISTA, Eraldo Leme \& LIMA, Marco Roberto. Os desafios da prática docente na perspectiva da pedagogia histórico-crítica: apontamentos para uma práxis transformadora da Educação. Germinal: Marxismo e Educação em Debate, Salvador, v. 7, n. 1, p. 168-177, jun. 2015.

BRASIL. Ministério da Educação. Lei de Diretrizes e Bases da Educação Nacional n ${ }^{\circ} 9.394$, de 20 de dezembro de 1996. Diário Oficial [da República Federativa do Brasil], Brasília, DF, v. 134, n. 248, 23 dez. 1996.Seção I, p. 27834-27841.Disponível em: <http://www.planalto.gov.br/ccivil_03/leis/19394.htm>. Acesso em: 10 mar. 2019.

BRASIL. Ministério da Educação. Lei no 11.091, de 12 de janeiro de 2005. Dispõe sobre a estruturação do Plano de Carreira dos Cargos Técnico-Administrativos em Educação, no 
âmbito das Instituições Federais de Ensino vinculadas ao Ministério da Educação, e dá outras providências. Diário Oficial [da República Federativa do Brasil], Brasília, DF, Seção 1 13/1/2005 Disponível em: < http://www.planalto.gov.br/ccivil_03/_ato20042006/2005/lei/111091.htm >. Acesso em: 10 mar. 2019.

DUARTE, A. J. Contribuições de Antônio Gramsci para a formação do trabalhador. Educativa, Goiânia, v. 9, n. 1, p. 99-110, jan./jun. 2006. Disponível em:

<http://seer.pucgoias.edu.br/index.php/educativa/article/view/78/74 >. Acesso em: 10 mar. 2019.

FRANCO, Kaio José Silva Maluf; CARMO, Aline Cristine Ferreira Braga do; MEDEIROS, Josiane Lopes. Pesquisa qualitativa em educação: breves considerações acerca da metodologia materialismo histórico e dialético. Revista Sapiência: sociedade, saberes e práticas educacionais (ISSN 2238-3565), v. 2, n. 2, p. 91-103, 2014.

FREITAS, Luiz Carlos de. Os reformadores empresariais da educação: da desmoralização do magistério à destruição do sistema público de educação. Educ. Soc., Campinas, v. 33, n. 119, p. 379-404, abr.-jun. 2012. Disponível em: < http://www.scielo.br/pdf/es/v33n119/a04v33n119.pdf>. Acesso em: 10 mar. 2019.

LIBÂNEO, José Carlos. Democratização da escola pública. Edições Loyola, 2001.

TRIVIÑOS, Augusto N.S. Introdução à pesquisa em Ciências Sociais: a pesquisa qualitativa em educação. São Paulo: Atlas, 1987.

VÁZQUEZ, Adolfo Sánchez. Filosofia da práxis. São Paulo: Expressão Popular, 2007.

Submetido em: 28/04/2019

Aprovado em: 10/06/2019 